\title{
Combined Prevention/Cessation Research
}

National Cancer Institute

\section{Source}

National Cancer Institute. Combined Prevention/Cessation Research. NCI Thesaurus. Code C15984.

Studies identifying, testing, and implementing interventions among groups of individuals that are designed to both prevent and stop current use of specific substances, such as tobacco or alcohol. (NCI/T RIP) 